\title{
A Dual-Band Printed Slot Antenna for WiMAX and Metrological Wireless Applications
}

\author{
Yaqeen Sabah Mezaal ${ }^{{ }^{*}}$, Seevan Fahmi Abdulkareem², Jawad Kadhim Ali $^{3}$ \\ ${ }^{1}$ Medical Instrumentation Engineering Department, Al- Esraa University College, Baghdad, Iraq \\ ${ }^{2}$ Computer Engineering Techniques Department, Al- Mansur University College, Baghdad, Iraq \\ ${ }^{3}$ Department of Electrical Engineering, University of Technology, Iraq \\ * E-mail: yakeen sbah@yahoo.com
}

\begin{abstract}
New printed slot antenna initiated from the portions of $1^{\text {st }}$ order structures of Sierpinski square geometry is modeled in this paper as a quasi-fractal device using an FR4 substrate of 4.4 dielectric constant, $1.6 \mathrm{~mm}$ thickness and 0.02 loss tangent. The intended antenna is designed for band frequencies of 3.5 and $7.8 \mathrm{GHz}$ for WiMAX and metrological satellite applications with a bandwidth of 0.66 and $0.78 \mathrm{GHz}$ for each band respectively. Also, it has interesting return loss and radiation results that can be employed in diverse wireless devices. Measured input reflection coefficient, radiation patterns, and gain results have been found in good agreement with those predicted by simulations.
\end{abstract}

\section{Introduction}

The accelerated development of wireless technologies has pioneered new demands for integrated components including microwave circuits like antennas. In modern wireless communication systems, low profile, dualband/multiband, small antennas, are hugely requested for military and marketable applications. Telecommunication system designers are also seeking for these types of antennas, which are dual-band/multiband or reconfigurable to other operating frequencies as looked-for. The fractal geometries, among many other techniques, can provide successful solutions for all these demands [1,2].

Fractal geometries are constructed using a particular formula with different curve orders which are called Iterated Function Systems (IFS). They are built from the sum of copies of itself; each copy has smaller copies from the previous orders [3]. The space-filling property of fractal geometries results in a reduced size antenna [4]. The selfsimilarity of the fractal structure leads to the multiband behaviour of the antenna because each of the substructures that constitute the antenna might have its resonance; some of the resulting resonances are coupled together to form the ultimate antenna dual-band or multiband responses. Fractal antennas can be remarkably miniature for applications requiring a fixed antenna or restricted in transparent materials to realize near-invisible larger-scale form factors [5].
In this context, microstrip and printed fractal antennas have been investigated widely in the literature using a variety of the standard fractal curves and their iterations like Koch, Sierpinski, Minkowski and Hilbert fractal geometries [6-8]. These antennas have functional band responses and practical radiation characteristics as well as their remarkable compactness. To enhance the bandwidths of the dualband/multiband antennas with fractal structures, Moore, Cantor, and Peano fractal geometries have been successfully applied as reported in [9-12]. Also, other fractal structures based on circles, half-circles, and keyshaped, have been adopted to design dual-band/multiband antennas for various wireless applications [13-15].

However, there are some applicable limitations of fractal antennas including numerical constraints, low gain, fractal iterations and design complexity [16]. These limitations can be solved by reformation techniques like fractal reconfiguration and like pre-fractal geometries [17-18]. These techniques are referred to semi or quasi-fractals which can be applied to antenna design, but not a mathematically fractal geometry with infinite scale. Consequently, quasi-fractal geometry with several iterations can be utilized for a particular dual/multiband antenna. Each frequency band is corresponding to a specific iteration of the fractal.

In this paper, a printed slot antenna using quasi-fractal geometry is proposed as a candidate for WiMAX and metrological wireless systems. This antenna is essentially simulated and experimentally investigated as dual-band device. The preparation of the quasi-fractal resonators has been constructed from an arrangement of the modified first order of Sierpinski fractal structures. Although the proposed structure is very close to Sierpinski square geometry, well known in the literature, the different approximation adopted for the pattern of the patch with feeding makes this topology different from the other studies. The designed antenna has dual-band response at 3.5 and $7.8 \mathrm{GHz}$ with reflection coefficients of -21 and $-15 \mathrm{~dB}$ for each band respectively.

\section{Antenna design}

The projected printed slot antenna is constructed from the $1^{\text {st }}$ order of Sierpinski fractal structure as shown in Figure 1 
[19]. The antenna topology is explained in Figure 2. The outline of this antenna is formulated from four portions of the modified $1^{\text {st }}$ order of Sierpinski formations, $C(1)$ as in Figure 1, joint with an inner smaller replica of the equivalent fractal order. This quasi-fractal resonator has been constructed within the ground plane, and the microstrip feed is within the upper plane. Miniature square slots are built in the corners of antenna resonator. The uniformity and symmetrical geometrical fashion of this antenna are reasons to refer it as a quasi-fractal structure. It can be assembled from the tiny square patch as design generator that has a length (L) of $1.5 \mathrm{~mm}$. Consequently, the main resonator length $(\mathrm{S})$ is $19.5 \mathrm{~mm}$. The dimensions of the substrate $(\mathrm{Wg}$ $\times \mathrm{Lg})$ are $26 \times 26 \mathrm{~mm}^{2}$. Single microstrip feed with $(\mathrm{Wf} \times \mathrm{Lf})$ dimensions of $1 \times 13 \mathrm{~mm}^{2}$ within upper plane has been employed for the depicted antenna as in Figure 2.
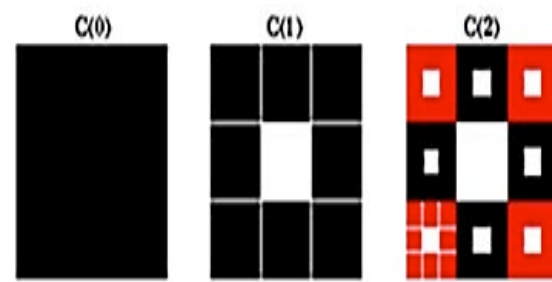

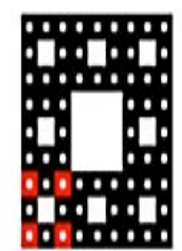

C(3)

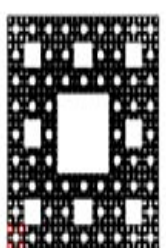

C(4)
Figure 1: The first five iterations of the Sierpinski carpet [19].

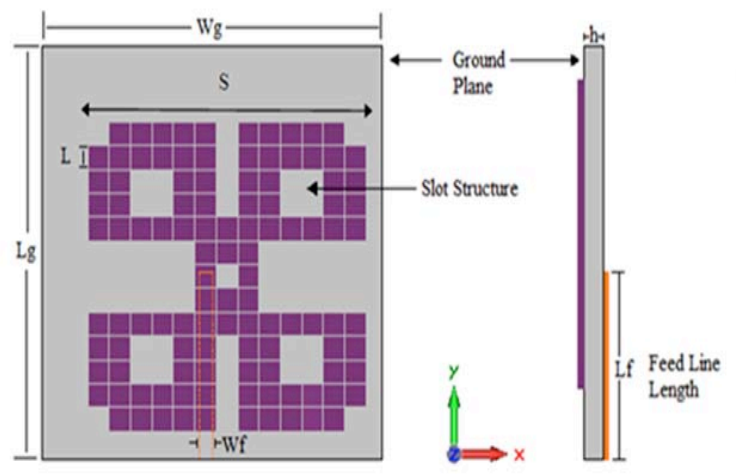

Figure 2: The quasi-fractal antenna topology.

The main advantage of the applied feeding type is the ease of assembly. It is a microstrip feed line that makes use of the antenna radiating element (the quasi-fractal structure) in its ground plane. Thus, this type of feeding is possibly the most appropriate among other methods, for the suggested antenna.

To determine the compression of antennas, these devices should comprise total dimensions in terms of guided wavelength that is calculated at the lower resonant frequency $(f)$ by $[20]$ :

$$
\lambda_{g}=\frac{c}{f \sqrt{\varepsilon_{e}}}
$$

where $c$ is the light speed and $\varepsilon_{e}$ is effective dielectric permittivity. The value of $\varepsilon_{e}$ can be evaluated by:

$$
\varepsilon_{e}=\frac{\varepsilon_{r}+1}{2}+\frac{\varepsilon_{r}-1}{2} \cdot \frac{1}{\sqrt{1+\frac{12 H}{W}}}
$$

$W$ and $H$ stand for conductor width and substrate thickness respectively. However, $\varepsilon_{e}$ can be calculated by the adopted EM simulator with a highly convergent result to Eq. (2). In this framework, the proposed antennas are simulated and verified using an FR4 substrate. Based on 'Trial and Error' procedure, the center frequency of designed antenna in this study can generally be varied by some attempts to reach to the intentional application bands by rescaling the quasi-fractal resonator dimensions inversely proportional to the design frequency. It is possible to optimize the electrical specifications of antenna response by inspecting proper feed width and length. These design principles and response optimization factors are agreed with the reported antenna designs in [1, 10-12].

\section{Simulation results and discussion}

All antenna designs have been simulated using Computer Simulation Technology (CST) software package. CST simulator offers proficient computational solutions for electromagnetic design and analysis. It carries out the electromagnetic investigation using Finite Difference Time Domain (FDTD) method.

For the proposed antenna depicted in Figure 2, its performance is determined within 1 to $10 \mathrm{GHz}$ swept frequency range using a substrate of 4.4 dielectric constant, $1.6 \mathrm{~mm}$ dielectric thickness and 0.02 loss tangents using feed line length and width of 13 and $1 \mathrm{~mm}$ respectively. It has been mainly intended at band frequencies of 3.5 and 7.8 $\mathrm{GHz}$ for WiMAX and metrological satellite applications as depicted in Figure 3. This antenna offers bandwidth ranges of 3-3.66 and 7.45-8.23 GHz for each band respectively, and exhibits return loss of -21 and $-15 \mathrm{~dB}$ for each band respectively. Accordingly, the fractional bandwidth (FBW) magnitudes with respect to $-10 \mathrm{~dB}\left|\mathrm{~S} \_1 \_1\right|(\mathrm{dB})$ at resonant frequencies are 18.86 and $10 \%$ for each $\bar{b}$ and respectively. 


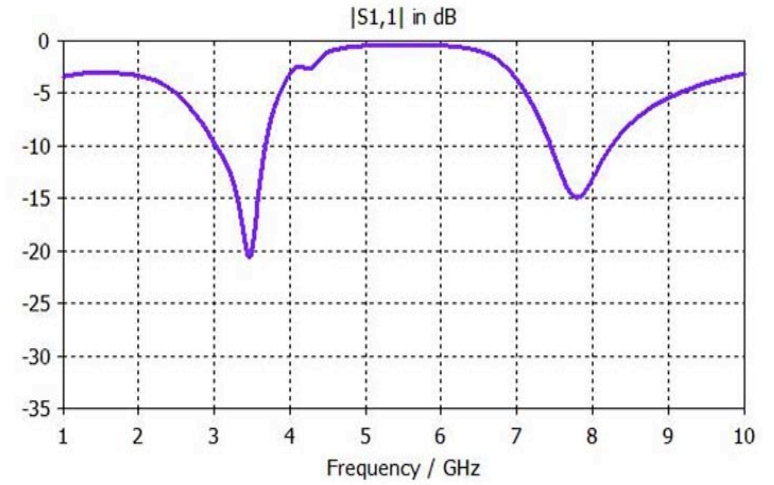

Figure 3: Dual band response of the proposed quasi-fractal antenna.

The self-similarity of the fractal structure leads to the dual/multiband performance of the antenna because each of the substructures that constitute the antenna might have its resonance; some of the resulting resonances are coupled together to form the antenna dual-band responses. Therefore, with the intention of acquiring further insight into the electromagnetic features of the quasi-fractal antenna, the simulated current distributions are generated at 3.5 and 7.8 $\mathrm{GHz}$ using feed line length of $13 \mathrm{~mm}$ as illustrated in Figure 4. As the responses of Figure 4(a) entails, the band frequency at $3.5 \mathrm{GHz}$ is attributed to the larger surface current pathway which is focused on the center edge of the structure to produce a lower resonance frequency. The band at $7.8 \mathrm{GHz}$ is interrelated with the shorter surface current pathway which is concentrated at the lower part of the structure as shown in Figure 4(b).

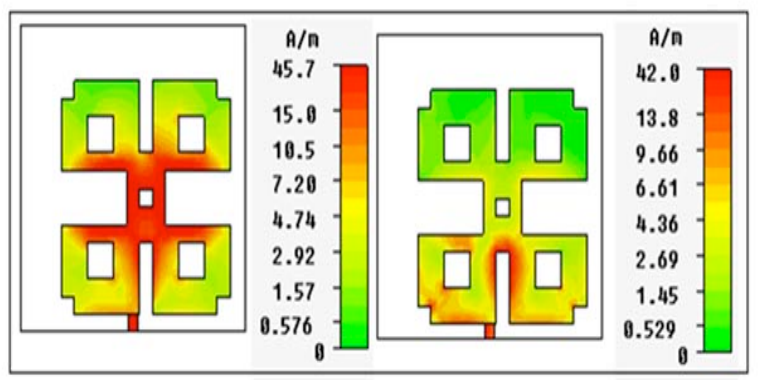

(a)

(b)

Figure 4: Current intensity distributions at (a) $3.5 \mathrm{GHz}$ and (b) $7.8 \mathrm{GHz}$

Figure 5 depicts the return loss parametric investigations of the proposed antenna with respect to feed line length. For several feed line lengths, the antenna has potentially dualband responses with reflection coefficients deeper than -10 $\mathrm{dB}$. As the feed line length increases from 11 to $17 \mathrm{~mm}$, the centers of lower frequency bands slightly change with different degrees of coupling corresponding to a feed line length variation, while the relevant bandwidths are decreased from 1 to $0.31 \mathrm{GHz}$. Conversely, longer feed line leads to lower the resonance frequency of the $2^{\text {nd }}$ band. It's due to the parallel capacity brought by the dielectric between the feed line and the radiation element. When this capacity increases (when the feed line is longer) the resonance frequency decreases. Maximum usable bandwidth of 0.86 $\mathrm{GHz}$ can be observed at 3.4 and $7.4 \mathrm{GHz}$ for lower and upper band frequencies. Within 11 to $17 \mathrm{~mm}$ feed length range, the usable upper band frequencies are higher than lower band frequencies since their S11 magnitudes are deeper than $-10 \mathrm{~dB}$ as shown in Table 1.

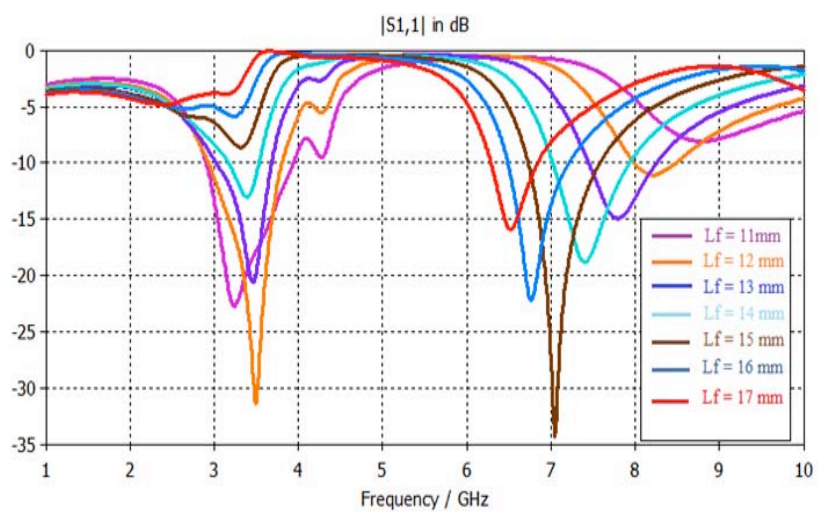

Figure 5: The return loss responses as a function of feed line length

Table1: Electrical specification with respect to feed line length variations

\begin{tabular}{ccccccc}
\hline $\begin{array}{c}\text { Feed } \\
\text { Length }\end{array}$ & F1(GHz) & F2(GHz) & S11(F1)dB & S11(F2)dB & BW1(GHz) & BW2(GHz) \\
\hline 11 & 3.44 & $\ldots \ldots$ & -23 & $\ldots \ldots$ & 1 & $\ldots \ldots$. \\
\hline 12 & 3.4 & 8.2 & -31.5 & -11.3 & 0.86 & 0.45 \\
\hline 13 & 3.5 & 7.8 & -21 & -15 & 0.66 & 0.78 \\
\hline 14 & 3.3 & 7.4 & -13.1 & -19 & 0.31 & 0.86 \\
\hline 15 & $\ldots \ldots$ & 7.1 & $\ldots \ldots$ & -34.4 & $\ldots \ldots$ & 0.8 \\
\hline 16 & $\ldots \ldots$ & 6.8 & -6.1 & -22.6 & $\ldots \ldots$. & 0.67 \\
\hline 17 & $\ldots \ldots$ & 6.5 & $\ldots \ldots$. & -16 & $\ldots \ldots$ & 0.52 \\
\hline
\end{tabular}

Figure 6 compares the reflection coefficient obtained with and without the quasi-fractal geometry (complete patch square). It is evident that the self-similarity of quasi fractal has electromagnetic motivation to generate dual-band response unlike single band response caused by the nonfractal approach. 


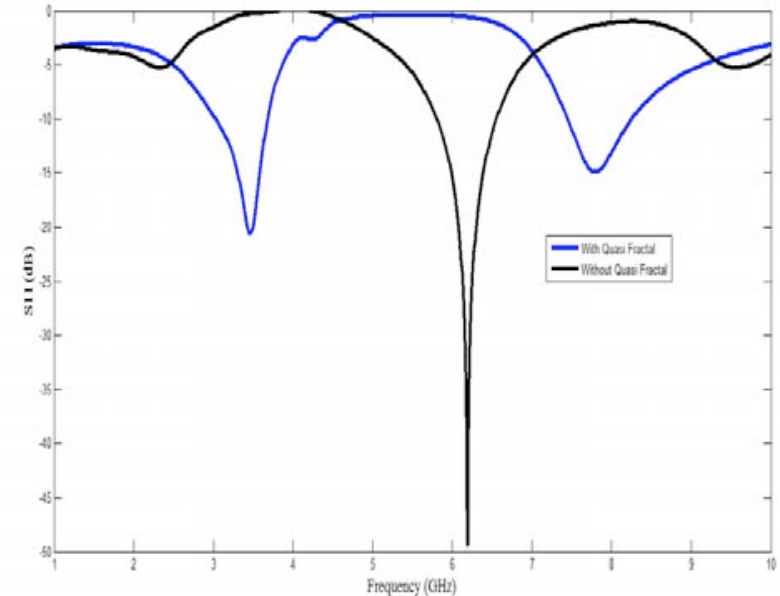

Figure 6 S11 responses with and without quasi-fractal approach for antenna design

Table 2 presents the comparison among the proposed quasifractal antenna and various dual-band and multiband antennas created by different design approaches in [21-25]. In addition to competing bandwidth percentage and gain, it can be exposed that the designed antenna in this study has an apparent compact size in $\mathrm{mm}^{3}$ in comparison with the other indicated studies.

\section{Measurement}

Figure 7 depicts the top and bottom views of the manufactured prototype of the designed antenna at 3.5 and $7.8 \mathrm{GHz}$ band frequencies. The measurement and simulation of $\mathrm{S} 11$ responses are both in fine consistency as shown in Figure 8 . The proposed antenna has substrate size of about $0.543 \lambda_{g} \times 0.543 \lambda_{g}$ at its lower band of $3.5 \mathrm{GHz}$ that can be integrated within many fixed and mobile wireless systems. In this respect, it is worth to note that the ratio of the upper to the lower frequencies at the resonant band centers is about 2.23. Consequently, by suitable dimension scaling of the antenna structure, many dual-band antennas can be designed. For instance, up-scaling of the antenna structure by about 1.46 in both dimensions can result in a dual-band antenna for $2.4 / 5.2 \mathrm{GHz}$ WLAN applications.

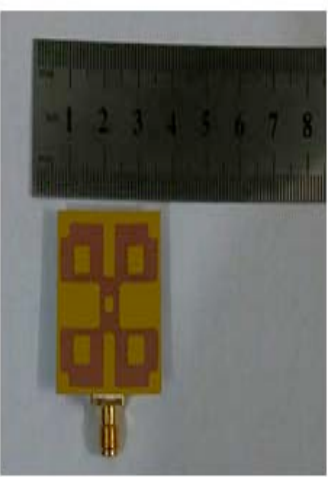

(a)

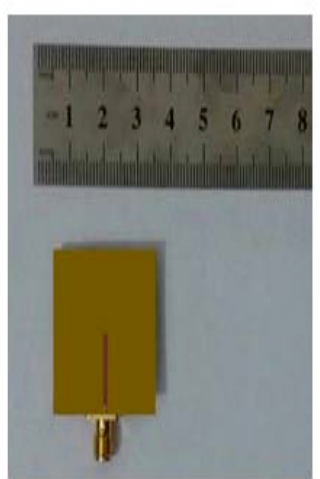

(b)
Figure 7 : (a) the top and (b) the bottom views of the fabricated antenna prototype.

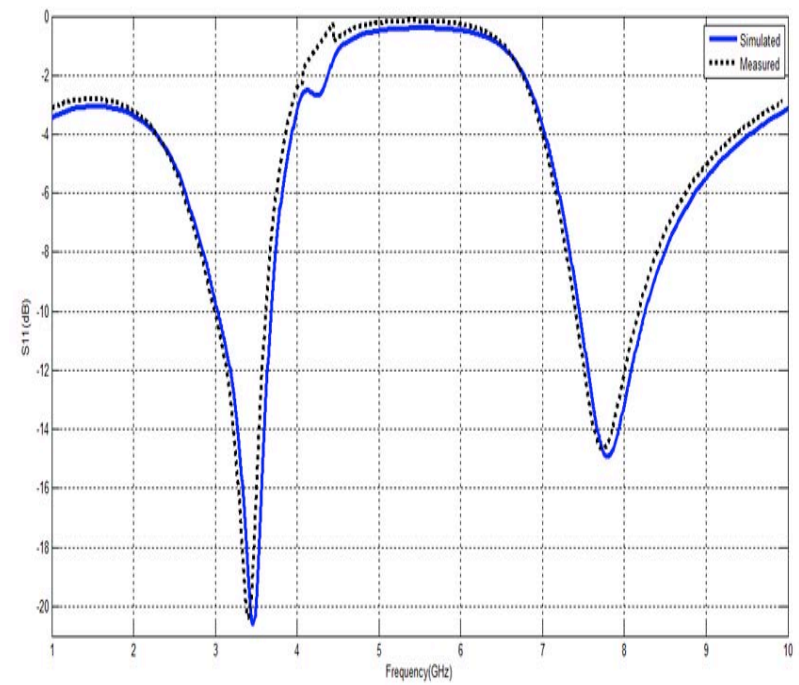

Figure 8: Simulated and measured S11 responses of the quasi-fractal antenna. 
Table 2 . Comparison with the recently published literature

\begin{tabular}{llllll}
\hline Ref. & size $\left[\mathbf{m m}^{3}\right]$ & No. of Res. bands & Res. freq. $(\mathbf{G H z})$ & Bandwidths $(\%)$ & Gain (dB) \\
\hline$[21]$ & $40 \times 40 \times 1.6$ & 3 & $1.5 / 3.5 / 5.4$ & $1.9 / 14 / 5$ & $-4.5 / 3.75 / 5.3$ \\
\hline$[22]$ & $18.8 \times 20 \times 0.76$ & 2 & $2.4 / 5.2$ & $1.6 / 23$ & $-1.7 / 2.4$ \\
\hline$[23]$ & $34 \times 18 \times 1.6$ & 3 & $2.5 / 3.5 / 5.5$ & $8.7 / 8 / 24.1$ & $-0.10 / 0.59 / 4.76$ \\
\hline$[24]$ & $100 \times 100 \times 0.8$ & 2 & $3.3 / 4.2$ & $12.1 / 4.8$ & $3.4-7.2 / 2.2-7.8$ \\
\hline$[25]$ & $50 \times 50 \times 1.0$ & 2 & $2.4 / 5.8$ & $45.9 / 12.7$ & $1.62-3.1 / 1.74-$ \\
& & & & $18.86 / 10$ & 1.78 \\
\hline Prop. & $26 \times 26 \times 1.6$ & 2 & $3.5 / 7.8$ & & $1.25 / 2-2.75$ \\
\hline
\end{tabular}

Figure 9 illustrates the simulated and measured electric field radiation patterns at 3.5 and $7.8 \mathrm{GHz}$ at $\mathrm{XZ}, \mathrm{XZ}$ and $\mathrm{YZ}$ planes. As it is perceptible from Figure 9, the measured radiation patterns are in fine agreement with those envisaged by CST simulator. Lastly, simulated and measured peak gain results are depicted in Figure 10 across the same band frequencies. At this point, just some frequencies are selected according to which a curve is drawn to explain the peak gain response in both bands. It is observable from this figure that measured peak gain curve is slightly lower than simulated one, that is because of manufacturing conditions and measurement environment. In this paper, we have used a commercially available FR4 substrate, for prototyping the model, because of its low-cost. The loss tangent of this substrate becomes more effective at the higher frequencies, and results in more losses and gives lower gain. This is the main reason for the deviation of the measured and simulated results over the upper resonant band. Gain can be improved by using others substrates with less losses since the dielectric losses can modify directly the antenna efficiency [26]. The dielectric constant will change the gain indirectly by reducing or not the effective surface of the antenna (for constant operating frequencies).

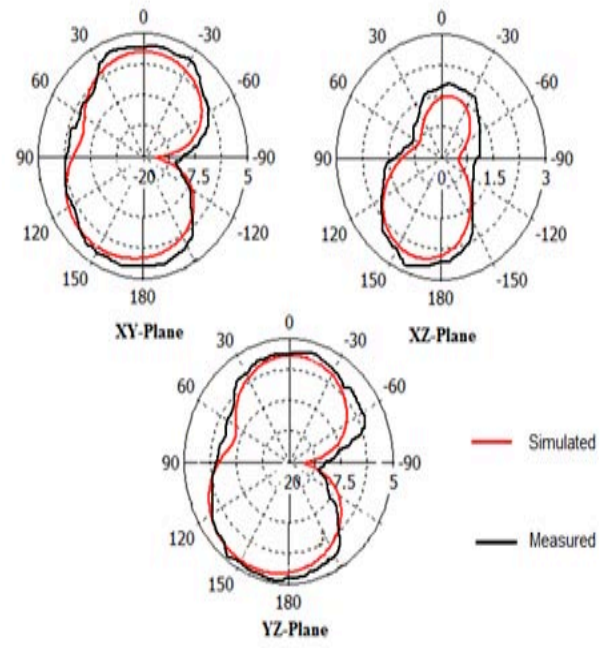

(a)

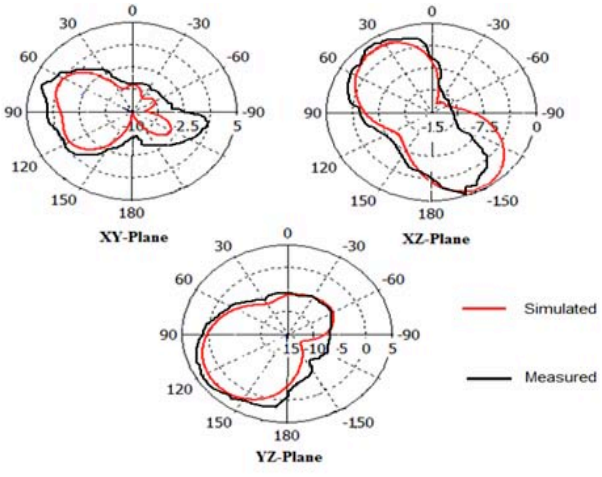

(b)

Figure 9: Measured (black) and simulated (red) far-field radiation patterns of the proposed antenna in the $\mathrm{YZ}, \mathrm{XZ}$ and $\mathrm{XZ}$ planes at (a) $3.5 \mathrm{GHz}$ and (b) $7.8 \mathrm{GHz}$.

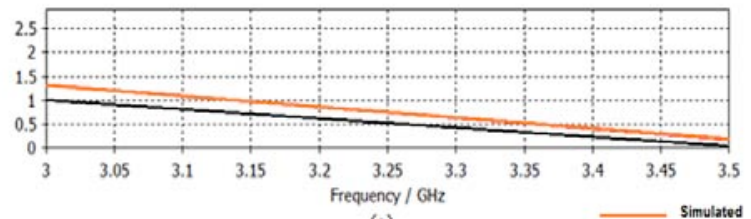

(a)
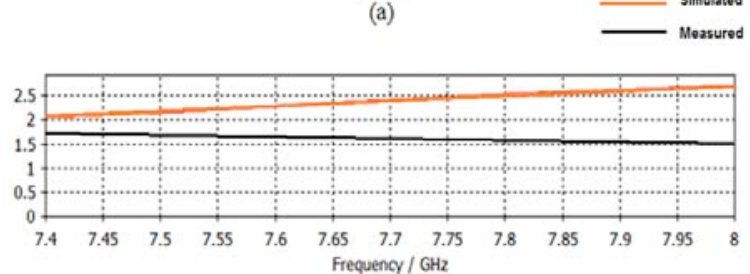

(b)

Figure 10: Measured and simulated peak gain values at (a) $3.5 \mathrm{GHz}$ and (b) $7.8 \mathrm{GHz}$.

\section{Conclusions}

In this research article, a new quasi-fractal printed slot antenna has been mainly designed as dual-band device at 3.5 and $7.8 \mathrm{GHz}$ center band frequencies for WiMAX and metrological satellite applications respectively. The antenna structure is based on the modified first order of Sierpinski fractal geometry. It offers bandwidth ranges of 3-3.66 and 7.45-8.23 GHz, and exhibits return loss values of -21 and $15 \mathrm{~dB}$ for each band respectively. The measured input 
reflection coefficient results have been found in good agreement with those predicted by the simulation. Furthermore, the proposed antenna has reasonably simulated and measured results throughout the resonant bands in terms of its radiation characteristics and the relevant peak gain. The proposed dual-band antenna is smaller in size than many reported antenna structures in the literature with competing fractional bandwidth and gain.

\section{References}

[1] Y. S.Mezaal,New Compact Microstrip Patch Antennas, Design and Simulation Results. Indian Journal of Science and Technology, 9, 12, 2016.

[2] J. Romeu and J.Soler, Generalized Sierpinski fractal multiband antenna. IEEE Transactions on Antennas and Propagation, 49, 8: pp. 1237 - 1239,2001.

[3] B. B. Mandelbrot,The Fractal Geometry of Nature, New York, W. H. Freeman, 1983.

[4] C.Z.C.Ghani,M.H.A.Wahab, N. Abdullah, S.A. Hamzah, A. Ubin, S.H. Dahlan, A.K. Anuar, K.N. Ramli, M.F. Alwi, Design Sierpinski Gasket Antenna for WLAN Application. Microwave Conference, APMC, Asia-Pacific, pp.1, 4, 11-14 ,2007.

[5] H. W.Douglas and S. Ganguly,An Overview of Fractal Antenna Engineering Research. IEEE Antennas and Propagation Magazine, 45, 1: 2003.

[6] C. Puente, J. Romeu, A. Cardama , The Koch monopole: A small fractal antenna.IEEE Transactions on Antennas and Propagation, 2000.

[7] J. Romeu, J. Soler, Generalized Sierpinski fractal multiband antenna. IEEE Transactions on Antennas and Propagation, 2001.

[8] I.S. Bangi, J.S.Sivia., Minkowski and Hilbert Curves Based Hybrid Fractal Antenna for Wireless Applications. AEU-International Journal of Electronics and Communications, 2018.

[9] J.K. Ali, A new microstrip-fed printed slot antenna based on Moore space-filling geometry,2009 Loughborough Antennas and Propagation Conference, LAPC 2009, Loughborough, 2009.

[10] J. Ali, S. Abdulkareem, A. Hammoodi, A. Salim, M. Yassen, M. Hussan, H. Al-Rizzo, Cantor fractal-based printed slot antenna for dual-band wireless applications, International Journal of Microwave and Wireless Technologies, 8, 2, 2016.

[11] S. Abdulkareem, A. Salim, A. Hammoodi, J. Ali, A Fractal-based Printed Slot Antenna for Multiband Wireless Applications, Proceedings of Electromagnetics Research Symposium, PIERS, Stockholm, Sweden, pp. 1047-1051, 2013.

[12] S. Abdulkareem, A. Salim, J. Ali, A. Hammoodi,T.Y. Mahmood, R.M. Husan, A Compact PeanoType
Fractal Based Printed Slot Antenna for Dual-band Wireless Applications, Proceeding of IEEE International RF and Microwave Conference, RFM, Malaysia, pp. 422-425, 2013.

[13] D.-C.Chang,B.-H. Zeng, J.-C. Liu, CPW-fed circular fractal slot antenna design for dual-band applications, IEEE Transactions on Antennas and Propagation,56,12: pp. 3630-3636, 2008.

[14] Y. K.Choukiker,S. Rai, S.K. Behera, Modified halfcircle fractal antenna using DC theorem for 2.4/5.2 $\mathrm{GHz}$ WLAN application, Proceedings of National Conference on Communication, IISc, Banglore, 2011.

[15] K. Devesh, Sh. Manish, B. Sakshi, Novel Design of Key-Shaped Fractal Antenna for UWB Applications, Sixth International Conference on Computational Intelligence and Communication Networks, pp.87-91.

[16] F. Viani, Dual-band Sierpinski Pre-Fractal Antenna for $2.4 \mathrm{GHz}$ - References $117 \mathrm{WLAN}$ and $800 \mathrm{MHz}-$ LTE Wireless Devices, Progress In Electromagnetics Research C, PIERS,35:pp. 63-71, 2013.

[17] Fractal Antenna Systems:

http://www.fractenna.com/nca_cohen_bio.html

[18] R.Ghatak, R.K. Mishra, D.R. Poddar, A. Patnaik ,Multilayered complementary quasi-fractal Sierpinski patch antenna for wireless terminals, URSI XXVIII GA Poster Presentations Programme, 95, 2005.

[19] Y.S. Mezaal, H.T.Eyyuboglu, J.K. Ali, New Dual Band Dual-Mode Microstrip Patch Bandpass Filter Designs Based on Sierpinski Fractal Geometry.In, Proceeding of Advanced Computing and Communication Technologies, Rohtak, India, pp.348352, 2013.

[20] D. M. Pozar, Microwave Engineering, $4^{\text {th }}$ Edition, John Wiley \& Sons, New Jersey, 2012.

[21] H. Rajabloo, V. A. Kooshki, H. Oraizi, Compact microstrip fractal Koch slot antenna with ELC coupling load for triple band application, $A E U$ International Journal of Electronics and Communications, 73: 144-149, 2017. https://doi.org/10.1016/j.aeue.2016.12.027

[22] A. A. Salih and M. S. Sharawi, A Dual-Band Highly Miniaturized Patch Antenna, IEEE Antennas and Wireless Propagation Letters, 15: 1783-1786, 2016. https://doi.org/10.1109/LAWP.2016.2536678

[23] L. Li, X. Zhang, X. Yin and L. Zhou, "A Compact Triple-Band Printed Monopole Antenna for WLAN/WiMAX Applications," in IEEE Antennas and Wireless Propagation Letters, 15: 1853-1855, 2016. doi: 10.1109/LAWP.2016.2539358 
[24] Snehalatha, L., N. Pathak, S. Manhas, reconfigurable multi-beam dual-band antenna based on Vee dipoles. Advanced Electromagnetics, 7: 19-24, 2018. doi.org/10.7716/aem.v7i2.724

[25] Fei, L., K. Xu, P. Zhao, L. Dong, and G. Wang, Uniplanar dual-band printed compound loop antenna for WLAN/WiMAX applications, Electronics Letters 53: 1083-1084, 2017. doi: 10.1049/el.2017.1543

[26] R. F. Harrington, Effects of antenna size on gain, bandwidth, and efficiency, Journal of Research of the National Bureau of Standards. Washington D.C. USA: US National Bureau of Standards, 1960. 